\title{
Research on the Brand Management Innovation of Middle and Small-sized Enterprises
}

\author{
Hongxia Sun \\ Weihai Vocational College, Weihai Shandong, 264210, China
}

Keywords: Middle and small-sized enterprises, Brand management, Innovation.

\begin{abstract}
Brand management is the important content of enterprises marketing management, also an important part of enterprise culture, the soul of enterprises' operation development, strengthening enterprises brand management is an important way to improve enterprise competitiveness. This paper studies the brand management innovation of middle and small-sized enterprises from three aspects of the important meaning, main existing problems and innovation strategies of brand management innovation.
\end{abstract}

\section{Introduction}

With the development and changes of market environment and media communication, consumer structure and consumption concept have also been affected greatly, under this background, people also pay more and more attention to enterprises images and brand reputation, brand management also becomes more and more important ${ }^{[1]}$. Enterprises brand management is a complicated process, it has an important meaning on enterprises’ sustainable development, especially for middle and small-sized enterprises with limited capacity, brand is an important tool to attract consumers, also an important power to strengthen enterprises internal management, therefore, middle and small-sized enterprises shall pay abundant attention on brand management innovation.

\section{The important meaning of middle and small-sized enterprises' innovative brand management}

Firstly, it can improve enterprises competitiveness: constructing brand with enterprises characteristics and positive brand management can strengthen enterprises' competition resistance to improve the competitive advantages of middle and small-sized enterprises, strengthening brand management can ensure enterprises' position in the industrial competition ${ }^{[2]}$. Secondly, it can stimulate enterprises' sustainable development: systematic and scientific brand management can increase enterprises' added value, fully play the brand advantages to attract more consumer groups to form brand effect, thus to stimulate the sustainable development. Thirdly, it can enhance enterprises' defensive power: strengthening brand management can help enterprises find their development direction, and definite their development goals, it is conductive to improve enterprises' operational and management level thus to enhance its resistance for market competition and risks.

\section{Analysis on the existing problems of middle and small-sized enterprises' brand management \\ Insufficient consciousness on brand management.}

Chinese middle and small-sized enterprises are usually lack of brand management consciousness, mainly manifested in two aspects, on one hand, they have no clear and deep understanding on brand and brand management, purely think that consuming a certain amount of money for brand promotion and reputation can form brand. They did not realize that the core value of brand and its covering enterprise culture are the fundamental motivation and source of brand effect ${ }^{[3]}$. On the other hand, they have deviation on the understanding on brand management, they did not combine market demand to do brand management but just blindly invest a large amount of financial resources, manpower and materials into the production and creation, which can only form white brand that 
familiar by market and consumers but cannot truly realize enterprises’ public praise and brand effects.

\section{Single brand management model.}

Most of the middle and small-sized enterprises focus on the pursuit of product sales, and rashly take single brand management marketing and communication means. In the aspect of brand marketing, most enterprises will choose periodic price war, through constantly reducing their product price to increase sales volume, this will obtain some economic benefit in a short term, but with more harm than good. On one hand it will damage the core value of the enterprise brand, on the other hand, it will worsen the industrial competition environment, affect market order, reduce consumers' trust on enterprise brand even the industry, finally it will make the enterprises brand be eliminated by the market with disturbance and fierce competition. On the aspect of brand communication, most of the middle and small-sized enterprises choose single advertising to promote brand awareness, but not fully use the current communication meanings with fast propagation speed, wide transmission range and new media with low cost, public relations, database marketing and knowledge marketing.

\section{Weak resistance on brand crisis.}

The main content of middle and small-sized enterprises' brand management mainly includes management on trademark registration, product patent, license and extension, while lack of impeccable brand management system, such as supervision and management system on brand, management mechanism of crisis warning, response plan for brand crisis and so on, low sensitivity on brand crisis, cannot effectively prevent and control the brand crisis, cannot take response measures when the brand crisis breaks out, and not strengthen effective communication with news media and consumer groups, this will not only worsen the crisis but also will speed up the elimination speed of the enterprises brand.

\section{Analysis on the strategies for middle and small-sized enterprises' brand management innovation}

\section{Operation model of the innovative brand management.}

1) Innovation on brand positioning

Brand positioning represents product identity and quality, accurate and suitable positioning can help enterprise brand enjoys popular support and stimulate the formation of brand effects ${ }^{[4]}$. Middle and small-sized enterprises should definite that constructing brand different from competitors is the main purpose of brand positioning, brand positioning should abide by the principles of clarity, accuracy and congruency, based on this to realize brand positioning innovation to form a different image in consumers' eyes. Firstly, enterprises should start from market target needs, combine enterprises resources and the market environment to optimize brand planning and positioning, the most important is the accuracy of positioning. For example, Wong Lo Kat once has an silent operation history over 7 years, mainly because it has no accurate positioning on the product, consumers are confuse whether this brand is "beverage" or "medicine", later it positioned it as herbal tea for preventing heat, it found the market value for the product, rapidly opened the domestic and overseas market. Secondly, brand positioning should select suitable methods and strategies. It can be positioned through emphasizing product functions and quality, also can through combining brand features and functions to combine with special context, for example, the water drops and snow mountains in the marketing advertising of Sprite, its purpose is to highlight its product feature of "penetrating coolness"; at last, pay attention the the difference from competitors, strengthen market survey, avoid positioning in the industries with monopoly brand, market saturation and same brand,deeply interpret brand connotation, development the core value of products, divide market find out the brand weakness of competitors, make use of every single space, pay attention to aspects of population aging, positively develop the elderly market to create special brand for elderly groups.

2) Innovation on brand communication model

Communication refers to transmit information to people through some ways, brand communication means to transmit brand information to consumers through various ways to help 
consumer understand the brand. Brand integrated communication means the process to integrate and manage related information of one enterprise brand, to unify the brand information, this is the important way for enterprises to construct and maintain brands, keep the communication consistency can realize mutual communication, middle and small-sized enterprises should carry out brand communication from various ways but not single advertising. For example, taking use of the communication model of brand touch points, that is the carrier of the core value, selling points of the same brand can be used for brand communication, is the brand product naturally noted by consumers. For example, through fully survey, “C\&S”under "P\&G” found that its target-consumers like watching entertainment channels, thus it achieves brand reputation from consumers by sponsorship to realize good brand communication effect. Coca-Cola Company provides sponsorship for the Olympic Games, Mengniu Dairy provides sponsorship for Super Girl, all these successful examples tell us that suitable usage of public relations can stimulate enterprises good images and also an effective way to construct brand image and brand effects.Middle and small-sized enterprises has limitations on resources and capitals, their brand communication mainly through magazine, newspaper, broadcast, $\mathrm{TV}$, guideboard and so on, but with the rapid development of internet technology can information technology, new medias like telephone, internet has gradually become the main way for information communication and with advantages like low cost, fast transmission speed, especially at present, the number telephone users is much larger than computer users, therefore,, middle and small-sized enterprises can use mobile phone media as the important way for brand communication.

\section{3) Innovation on the coping mechanism of brand management crisis}

Enterprises managers should update management philosophy, improve crisis management consciousness, combine their own development and resource structure to scientifically and rationally make brand crisis management system and response plan, mainly includes crisis prevention, communication and response plan, definitely point responsible person for crisis treatment, once brand crisis happens they can use enterprises resources to make response plan and carry out rehearsal. When make response plan for the crisis, they should analyze the development situation of crisis from different angles, prepare for the worst situation and research out corresponding counter measures, establish complete product recall and compensation system to reduce the brand crisis loss to the minimum. Besides enterprises' internal management and improving crisis coping capacity, they should also consider competitors, consider their possible response and their impact and make a pointed plan. The transmission speed of brand crisis information is very fast, enterprises managers should have high sensitivity on various medias, first to understand the reason, process and impact of the crisis once it breaks out, analyze its impacts on consumers, enterprises brand and other aspects and immediately take relevant measures. Make out the communication strategies for social public, consumers and medias to avoid hurry after the crisis and to ensure all the saving works can be carried out in order and to maximum reduce the loss.

\section{Innovation on the enterprises organizational structure.}

Middle and small-sized enterprises should think about the restructuring and optimization settings of the enterprises organizational structure from the innovation aspect, combine enterprises' phased and terminal goal to integrate the public relations, advertising, marketing and other functional departments, establish a unified and standard brand management organizational structure, implement brand manager system and arrange specialty staff responsible for the strategic plan and supervision of brand management work. Two factors should be fully considered when integrate the innovative enterprises' brand management organizational structure, one is marketing factor, its purpose is to optimize brand profiting model and the communication model, improve the loyalty, reputation and awareness of brand in the market and the consumers to improve market share; the second is technology, its purpose is to furtherly improve scientific content after the resources optimization, optimize brand function to ensure brand quality. Brand management organizations can innovate from fives aspects of technology management, marketing management, design management, resource management and cultural ecological management, promote the integrated dynamic management of brand management from product design, brand marketing and brand effects, to improve enterprises brand core value and competitive advantages. Firstly, pay attention to the ecological activity and 
durability of brand to make enterprises brand be with the resisting capacity and resisting durability to compete with competitors, maintain the market share of the brand to guarantee the brand economic benefit; secondly, pay attention to the brand property right protection, including technology skills, brand core technology, cultural features, all of these should apply patent protection through effective legal procedures; thirdly, pay attention to the dynamic adaptive capacity of the brand, market environment is changeable, therefore, enterprises should be with adaptive capacity and strain capacity to maintain their advantages in the market; fourthly, pay attention to cooperative symbiosis of the brand, fully consider the formation and development situation of the brand ecological chain in the whole market, make enterprises brand can be cooperatively developed in the multiple layers brand ecological system, maintain the brand loyalty guarantee the constant brand profit to realize mutual benefit and win-win result.

\section{Innovation on talents training model.}

Talent is the indispensable important factor for enterprises production and development, therefore, we should strengthen middle and small-sized enterprises' brand management, innovate the brand management and pay attention to the innovation on talents training model to optimize and enrich enterprises' talents structure. Firstly, strengthen new staffs' enterprises culture studying and quality education, establish correct value concepts, improve their cognition and identity on enterprises cultures, improve sense of mission and responsibility. Secondly, combine the development status to constantly improve staff training and development system, positively innovative, such as combine unified training with small group training, relevant enterprises management system and staff's ethical quality can be carried out together; professional talents, like public relation department, HR department, design department, marketing department can receive small group training, improve their professional ability at the same time with improving their comprehensive quality. Thirdly, complete staffs' further education system, and realize further education for complied staffs through various ways, such as study professional knowledge in domestic and overseas famous universities, realize communicative studying with relevant industries to cultivate more professional, technological and practical talents for enterprises.Fourthly, strictly implement enterprise talent selection system, not employ people whose comprehensive quality is under the standard, strictly criticize staffs who damaged the enterprises brand, completely eradicate same kind of behaviors, optimize talents structure to promote the establishing of enterprises good brand image.

\section{Conclusion}

No matter on capital, scale nor comprehensive strength, middle and small-sized enterprises in China need a further development, while only improve core competence of enterprises can help them survive in the changeable and fierce competitive market environment and achieve stable and sustainable development. During this process, enterprises brand has an important function, brand is the soul and important dynamic for enterprises development. Therefore, middle and small-sized enterprises should pay much attention on brand management, actively study from the overseas successful cases, from brand positioning, brand communication model, talents cultivation model to constantly optimize their own brand management, improve enterprises core value and competitiveness to form good brand effect to realize constant increase on market share to improve enterprises economic benefits.

\section{References}

[1] Gai Hongwei, Tong Linjie. Innovation on the Brand Development Strategy of Middle and Small-sized Enterprises in the Internet Era, Commercial Times, 2014(13):65-66.

[2] Zhen Zaifeng, Lao Chengqiang. Analysis on the Innovation Ways of Middle and Small-sized Enterprises in ShenZhen High-tech Zone, Practice and Theory of Sezs, 2015(04):80-86. 
[3] Qiu Mingfeng. Brand Management Innovation and Enterprises' Sustainable Development Ways[J] Commercial Time, 2014(22):103-104.

[4] Sun Renxiang. Discussion of Micro Innovation Promoting the Middle and Small-sized Enterprises’ Core Competitiveness, Academic Communication, 2013(07):123-126. 